\title{
Impact Factors in a Curriculum Vitae for Scholarship Application
}

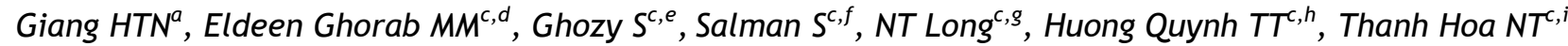
Kim Anh $N T^{c, j}$, Cam Tien $T T^{a, c}$, Kieu Linh $D T^{c, h}$, Sa $N Y^{c, j}$, Huy Vu $T L^{c, k}$, Elshafie $A^{c, d}$, Abdelkhalek $M^{c, l}$, Iyad AlMidani $O M^{c, m}$, Hirayama $K^{n}$, Huy $N T^{o, p}$

${ }^{\text {a}}$ Faculty of Medicine and Pharmacy, The University of Danang, Danang, Vietnam

${ }^{\mathrm{b} C}$ Center for International Health, Ludwig Maximilian University of Munich, Germany

'Online Research Club

${ }^{\mathrm{d}}$ Faculty of Medicine, Alexandria University, Alexandria, Egypt

${ }^{\mathrm{e}}$ Faculty of Medicine, Mansoura University, Mansoura, Egypt

${ }^{\text {f}}$ Tanta University Hospital, Tanta, Egypt

${ }^{\mathrm{g}}$ Hanoi Medical University, Hanoi, Vietnam

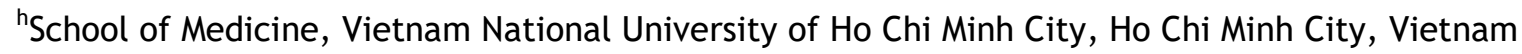

${ }^{i}$ Faculty of Pharmacy, University of Medicine and Pharmacy, Ho Chi Minh City, Vietnam

jPham Ngoc Thach University of Medicine, Ho Chi Minh City, Vietnam

${ }^{k}$ Advanced Research Center, Inc., Anaheim, California, USA

'Faculty of Medicine, Tanta University, Egypt

${ }^{\mathrm{m}}$ College of Medicine, University of Sharjah, Sharjah, UAE

nDepartment of Immunogenetics, Institute of Tropical Medicine (NEKKEN), Leading Graduate School Program, and Graduate School of Biomedical Sciences, Nagasaki University, Nagasaki, Japan.

${ }^{\circ}$ Evidence Based Medicine Research Group \& Faculty of Applied Sciences, Ton Duc Thang University, Ho Chi Minh City, 70000, Vietnam

${ }^{P}$ School of Tropical Medicine and Global Health, Nagasaki University, Nagasaki 852-8523, Japan.

\section{ABSTRACT}

Introduction: Scholarship applicants often receive different advice on what should be included in their Curriculum Vitae (CV). This study aims to investigate what the essential components of a CV being prepared for scholarships are, how to present them, and what their level of impact is. Materials and Methods: The authors sent an online structured questionnaire to 7512 corresponding authors of recent published papers in Scopus; 124 completed questionnaires were returned. Recommended elements for a CV were chosen according to the Delphi consensus technique with a threshold of $50 \%$. Results: This survey revealed that headings, bullet points and careful error checking were essential parts of the layout. For the content of the $\mathrm{CV}$, besides publications, education and training background, research experience and research interest were also necessary. Moreover, almost all respondents ranked publications as the most important qualification of an academic scholarship candidate. Publications also came first as the most impressive factor, followed by awards and honours. The number of publications, quality of journal, impact factor and total citation should be presented in publication section. The importance of publications in getting academic scholarships is significantly emphasized in this recent study. Conclusions: Having research experience and papers in peer review journals, are highly recommended for students seeking academic scholarships.

KEYWORDS: Curriculum Vitae, Scholarship, Academic, Research, Education.

Corresponding Author:

Dr. Nguyen Tien Huy

School of Tropical Medicine and Global Health, Nagasaki University, Nagasaki 852-8523, Japan. Telephone: Nil

Email: tienhuy@nagasaki-u.ac.jp

\section{INTRODUCTION}

With an increasing demand for higher education a wide range of scholarships are currently available in a bid to make graduate and post-graduate education more affordable and motivate individuals in further studying and research. ${ }^{1}$ Apart from prestigious 
government scholarships such as Fulbright program, Erasmus Mundus Program, Endeavour Scholarships and Fellowships, scholarships sponsored by universities and professors are also worth mentioning. Although the scholarship review process may vary depending on the scholarship, three main sections, including the Curriculum Vitae (CV), statement of purpose, and recommendation letter are generally considered in the application. A CV is an outline assessment of a person's background education, experience, skills, and achievements. It also plays an important role in scholarship applications for graduate and post-graduate programs. ${ }^{2,3}$ It is the primary impression for reviewers and scholarship selection committee, in which both the layout and contents of the CV could be used for shortlisting candidates. Receiving an academic scholarship is highly competitive, and applicants should better present their CVs in such a manner that distinguishes them from other candidates. ${ }^{4}$ The art of writing an impressive $\mathrm{CV}$ is not just listing all experiences and achievements. ${ }^{4}$ However, students often receive conflicting advice on what should be included in an academic CV and what makes it more impressive. Furthermore, CV requirements may be different in each academic field, in which medicine is not an exception. ${ }^{5}$ Although CV assessment in academic medicine is an important way of performance evaluation, mistakes in preparing medical CVs have been reported. ${ }^{6,7}$ Surprisingly, to the best of our knowledge, there is limited amount of scholarly evidence and supporting data to address the question of how to write a good CV for academic scholarships and grants in medicine. ${ }^{8,9}$ Thus, this study aimed to determine the essential items to be included in an academic medical $\mathrm{CV}$ as well as their recommended presentation, and find out the most important academic qualifications and achievements that could help applicants get scholarships for post-graduate study and research.

\section{MATERIALS AND METHODS}

\section{Research instrument}

We conducted an anonymous email-based survey using a self-administered questionnaire containing items on the demographics of the respondents, layout, and content of a CV. These questions were designed based on the questionnaire of previously published studies and were formatted as multiple choice or 5-point Likert scale in an online Google Forms presented via the link http://goo.gl/forms/ mGNsrtBjbP. ${ }^{10-15}$ There were some open questions asking for the opinions of the respondents on the essential elements that an impressive CV should include and the key features and achievements the respondents usually focus on when they make their decision regarding scholarship applications. The questionnaire was thoroughly reviewed by a panel comprising of two experts who have reviewed CVs for academic scholarships and two candidates who had succeeded in applying for a scholarship in medicine. Based on panel reviews, modifications were carried out with regards to content, arrangement and structure of questionnaire. In addition, to ensure the reliability, two pilot surveys were conducted with 23 members of Online Research Club (http:// www.onlineresearchclub.org/) using a Google Forms to identify any weaknesses and grammar or typing errors, based on which the questionnaire was finalized accordingly. Information collected included authors' nationality as well as whether they have reviewed CVs, recruited students, supervised international students, and participated in a scholarship selection committee. No personal information was collected.

\section{Participants}

The target population in this study was corresponding authors of medical papers indexed in Scopus in 2016 to obtain specific advice for students who plan to apply for post-graduate scholarships in the medical field. These authors were identified using the following search structure: TITLE-ABS-KEY (a) AND (LIMIT-TO (PUBYEAR, 2016)) AND (LIMIT-TO (SUBJAREA, "MEDI"). Information of the first 10000 papers was downloaded in RIS format and loaded into an excel spreadsheet. The research team then searched for corresponding authors' emails manually from either Scopus or journals of these publications. For papers with more than one corresponding authors, the last person in the author list was selected for emailing. Among these papers, 8320 had email addresses (83\%), 808 duplicated emails were removed, and 7512 emails were sent out to corresponding authors. A cover letter was included in the email, explaining our research question and the anonymity of study participants. The first question in the questionnaire was designed as an informed consent form. Two other follow up emails were sent to remind the recipients seven days after the first 
email was sent. Eventually, there were 127 responses received. The entire process is summarized in Figure 1. Information collected includes authors' nationality, and whether they have reviewed CVs, recruited students, supervised international students, and participated in a scholarship selection committee.

\section{Data analysis}

Data was collected into a spreadsheet and analysed using the R Statistical Language. Standard descriptive measures were calculated for each question or item individually. Items that were answered by more than $50 \%$ of respondents were recommended to be included in a CV according to the Delphi consensus method with a cut-off value of $50 \%$. For questions that used the 5-points Likert scale, items that had more than $50 \%$ of respondents choosing the agreement or the strong agreement were recommended to be included. In the analysis, Chi-square test was used to determine the significant difference between groups. A probability of less than 0.05 was considered significant.

\section{RESULTS}

\section{Characteristics of respondents}

Among 7512 corresponding authors targeted, 124 responded to the questionnaire with a response rate of $1.7 \%$. One respondent was excluded since the majority of answers to the questions were incomplete; thus, data from 123 respondents were suitable for analysis (Figure 1). All participants were from 41 countries in five continents, and nearly half (48\%) were from Europe (Table 1). Approximately two-thirds of the participants (64\%) have served as an external reviewer to evaluate a student's CV, and more than one-third have served as a member of a scholarship selection committee. The number of CVs they had reviewed ranged from 0 to over 1000 . Twothird of all respondents (67\%) have recruited from one to more than 100 students for Ph.D., Masters or research programs.

\section{The layout of an academic CV}

There was no significant difference between the answers of respondents with experience in reviewing $\mathrm{CV}$ and those without to questions related to the layout of an academic CV, except for their responses for whether or not a photo should be inserted. More than 84 respondents $(68 \%)$ chose headings and bullet points as an essential part of the CV. Careful checking for spelling and grammatical errors was recommended by 97 respondents (79\%). Regarding the presence of candidates' photographs on their CVs, there were 68 respondents (55\%), in which 55 (44.7\%) were located in Asia and Europe, who recommended this item. In contrast, $82 \%$ of respondents from the Americas advised not to put a photograph on the CV. This difference was statistically significant (Chi square test, $p=0.001$ ). A lower proportion of respondents with experience reviewing CVs advised to insert a photo, compared to those without such experience (48.1\% and $68.2 \%$ respectively, $p=0.03$ ). The majority of the respondents $(n=52,42 \%)$ answering the question about number of pages selected the option "It depends on the content of the CV". Noticeably, 104 of corresponding authors (85\%) thought that the CV should have an entirely separate section for publications, with a significantly higher proportion recorded in respondents with CV reviewing experience compared to those without $(89.9 \%$ and $75 \%$ respectively, $p=0.03)$. In contrast, the majority of respondents did not advise using separate title pages (61\%) and summary table (72\%). Regarding the type of CV, one-third of respondents recommended using chronological order, but the other one-third recommended using reversed order.

\section{Contents of an academic CV}

A similarity was recorded in almost all advice related to the contents of an academic CV between respondents with and without experience in reviewing CV. A significant difference was only found in opinions on h-index. In general, 88 respondents $(72 \%)$ suggested that CVs should focus on accomplishments relevant to the scholarship. The perspectives of respondents on specific sections of the CVs were described in detail as following.

\section{Elements of a CV}

The majority of the participants reported that publications, education and training background, as well as personal information were essential in candidates' CVs (96\%, 94\%, 78\% respectively). In addition, work experience, teaching experience, 
awards and honours, proof of language proficiency, personal skills and competence, and referees should also be included as suggested by most respondents. The percentages of responses for each item are provided in Table II.

\section{Education and training background}

Education background including undergraduate, postgraduate, research and training courses, and workshops were agreed to be essential for a CV by $80 \%, 97 \%, 87 \%$, and $62 \%$ of respondents respectively.

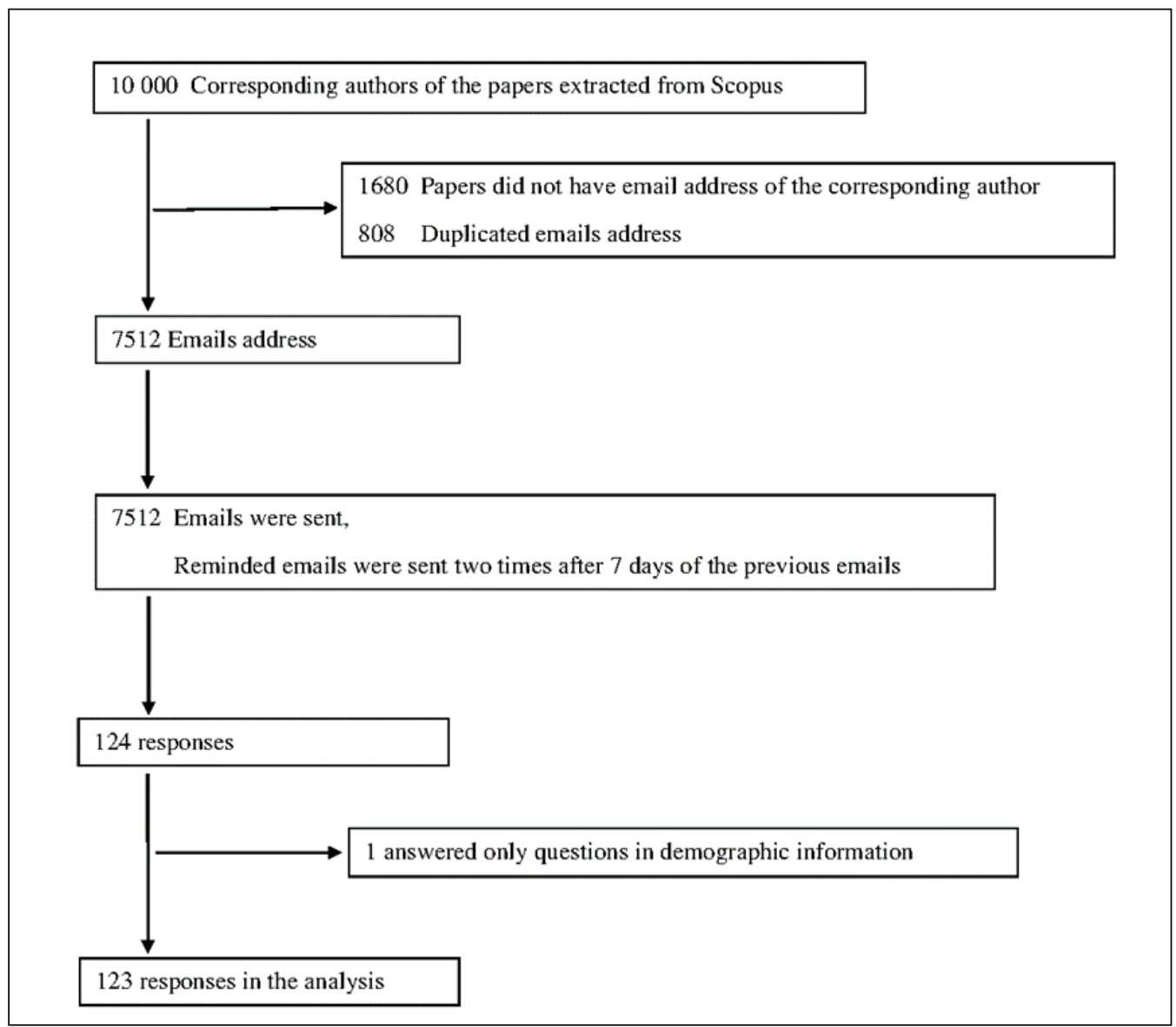

Figure 1: Flowchart showing the entire process for selecting target population, email progression, and final number of respondents included into data analysis for Curriculum Vitae survey conducted in 2016.

\section{Personal details}

Considering the specific items within the personal information section of the CV, $116(97 \%)$ respondents preferred to know name and email address. Additionally, date of birth, phone number, home address, nationality and gender were considered essential inclusions. However, religion, marital status, and driving license were not recommended to be included by the majority of respondents. It is interesting to mention that there were three respondents who wanted to know whether candidates had children and/or dependent. Hobbies, strengths and weakness; society memberships; and community services and volunteer work; were advised to be excluded in an academic by $80 \%, 75 \%$ and $54 \%$ of the respondents respectively.
Eighty-five percent of the respondents $(n=104)$ recommended candidates to specify the level of their grade point average (GPA), and the national and international rankings of students' university were also advised to be included by $56 \%$ respondents.

\section{Publications}

Most respondents (98\%) preferred candidates to show their peer reviewed articles, yet some of the respondents also considered non-peer reviewed articles, book chapters, and books $(62 \% ; 72 \%$; $72 \%$ respectively). In addition, the number of publications, quality and impact factors of research journals, h-index and total citation of candidates 
were considered somewhat important to mention in candidates' CVs $(85 \%$; $58 \%, 59 \%, 36.6 \% ; 44.7 \%$ respectively). A higher number of respondents who were experienced in reviewing CVs advised to include h-index in the publication's information, compared to those without such experience $(45.6 \%$ and $20.5 \%$ respectively, $\mathrm{p}=0.005$ ). More than $95 \%$ of respondents did not include $z$-index $(n=117)$ and $m$-index $(n=118)$ as essential information for a CV. Furthermore, respondents specified that they used Web of Science $(77 \%)$, Scopus (76\%), and Google Scholar $(67 \%)$ to figure out candidates' $h$-indexes. Four respondents added PubMed and Research Gate as alternative sources for $\mathrm{h}$-index determination.

Table I: Characteristics of 123 respondents in the curriculum vitae survey conducted in 2016

\begin{tabular}{lcc}
\hline Characteristics & $\mathrm{n}$ & $\mathbf{( \% )}$ \\
\hline Continent where the respondent works & & \\
$\quad$ Europe & 59 & $(48.0)$ \\
$\quad$ Asia & 30 & $(24.4)$ \\
The Americas & 22 & $(17.9)$ \\
$\quad$ Africa & 8 & $(6.5)$ \\
$\quad$ Australia & 3 & $(2.4)$ \\
$\quad$ Unknown & 1 & $(0.8)$ \\
Has served as an external reviewer to & 79 & $(64.2)$ \\
evaluate CVs & & \\
$\begin{array}{l}\text { Has been a member of selection } \\
\text { committee }\end{array}$ & 48 & $(39.0)$ \\
$\begin{array}{l}\text { Has recruited students for Ph.D., } \\
\text { Master's or research programs }\end{array}$ & 82 & $(67.2)$ \\
Has supervised international students & 73 & $(59.3)$ \\
\hline
\end{tabular}

\section{Conference papers}

The opinions of respondents were diverged regarding conference papers. Specifically, this item was recommended to be included in the CV by $58 \%$ of the respondents. More than half of the respondents (56\%) did not consider conference papers as publications and recommended to separate them from peer reviewed articles in the conference and meeting section. However, a third of respondents (35\%) reported that this issue depended on the type of conferences.
Table 2: Respondents advising of what should be included in an academic CV

\begin{tabular}{|c|c|c|}
\hline Items & Respondent, $\mathrm{n}$ & (\%) \\
\hline Personal information & 93 & $(77.5)$ \\
\hline Name & 116 & $(96.7)$ \\
\hline Date of birth & 103 & $(85.1)$ \\
\hline Email address & 119 & $(96.8)$ \\
\hline Phone number & 100 & $(82.0)$ \\
\hline Home address & 73 & $(60.9)$ \\
\hline Nationality & 101 & $(82.8)$ \\
\hline Gender & 89 & $(74.1)$ \\
\hline Religion & 15 & $(12.8)$ \\
\hline Marital status & 30 & $(25.0)$ \\
\hline Driving license & 17 & $(14.5)$ \\
\hline $\begin{array}{l}\text { Education and training } \\
\text { background }\end{array}$ & 114 & $(94.2)$ \\
\hline $\begin{array}{l}\text { High school } \\
\text { information }\end{array}$ & 55 & $(45.8)$ \\
\hline $\begin{array}{l}\text { Undergraduate } \\
\text { information }\end{array}$ & 98 & $(79.7)$ \\
\hline $\begin{array}{l}\text { Postgraduate } \\
\text { information }\end{array}$ & 119 & $(96.7)$ \\
\hline $\begin{array}{l}\text { The grade "Very good } \\
\text { or above" }\end{array}$ & 104 & $(84.5)$ \\
\hline $\begin{array}{l}\text { Research educational } \\
\text { courses }\end{array}$ & 107 & $(87.0)$ \\
\hline $\begin{array}{l}\text { Level in national or } \\
\text { international } \\
\text { classification of the } \\
\text { candidate's university }\end{array}$ & 68 & $(55.7)$ \\
\hline Management courses & 68 & $(56.2)$ \\
\hline All training courses \& & 76 & $(62.3)$ \\
\hline Publications & 118 & $(95.9)$ \\
\hline Peer reviewed articles & 120 & $(97.6)$ \\
\hline $\begin{array}{l}\text { Non peer reviewed } \\
\text { article }\end{array}$ & 47 & $(38.2)$ \\
\hline $\begin{array}{l}\text { Abstracts of } \\
\text { conference }\end{array}$ & 71 & $(57.7)$ \\
\hline Chapters & 88 & $(71.5)$ \\
\hline Books & 88 & $(71.5)$ \\
\hline Work experience & 114 & $(92.6)$ \\
\hline Research experience & 117 & $(95.2)$ \\
\hline Teaching experience & 111 & $(90.3)$ \\
\hline Awards and honours & 101 & $(82.1)$ \\
\hline Proof of language proficiency & 87 & $(70.7)$ \\
\hline $\begin{array}{l}\text { Personal skills and } \\
\text { competence }\end{array}$ & 91 & $(75.2)$ \\
\hline $\begin{array}{l}\text { Hobbies and free-time } \\
\text { activities }\end{array}$ & 24 & $(19.8)$ \\
\hline Strengths and weakness & 30 & $(24.8)$ \\
\hline $\begin{array}{l}\text { Society memberships, } \\
\text { community services, } \\
\text { volunteer work }\end{array}$ & 56 & $(45.5)$ \\
\hline $\begin{array}{l}\text { Research interest and } \\
\text { ambition } \\
\text { References }\end{array}$ & $\begin{array}{l}87 \\
91\end{array}$ & $\begin{array}{l}(71.3) \\
(74.0)\end{array}$ \\
\hline
\end{tabular}




\section{Elements of an impressive $\mathrm{CV}$}

Regarding the first item looked at when reviewing an academic CV for a scholarship, the respondents selected publications (39\%), education and training background (32\%), and research experience $(16 \%)$ as shown in Figure 2. In response to which item was looked at in the publication section, $25 \%$ of respondents selected the number of publications, while more than $30 \%$ focused on papers published in journals indexed by Web of Science (ISI) and the impact factor of those journals. No respondents chose $\mathrm{z}$-index or $\mathrm{h}$-index as an indicator for their decision. Regarding the priority in qualifications of candidates for academic scholarships, most of the respondents ranked publications as one of the most important items (95\%), followed by awards and honours (67\%), communication skills (66\%), teaching experience (58\%), GPA (58\%) and graduate record examination (GRE) score (58\%) (Figure 3). Surprisingly, more than three quarters of the respondents did not consider volunteer work as important. There were $58.7 \%$ of respondents with CV-reviewing experience who ranked communication skills as important, while the percentage of non-experienced respondents in CV reviewing was $79.1 \%(p=0.02)$.

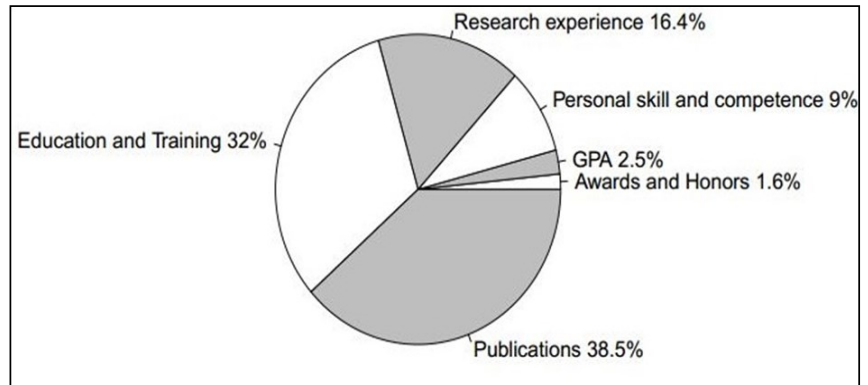

Figure 2: The proportion of respondents looking first important factor in the review of a CV

\section{DISCUSSION AND CONCLUSIONS}

In general, data obtained from 123 completed survey responses, strongly suggest that publication is the key feature that makes a CV impressive towards the selection committee. Moreover, our findings provide a framework for what scholarship applicants should include to make their $\mathrm{CV}$ more distinguishable from other applicants.

Considering the amount of other research conducted on this topic during the last 20 years, present studies have suggested that publication has always been the essential concern for a competitive candidate. . $^{311,12}$
Most respondents in the current survey indicated that they were attracted mostly to publications, especially peer-reviewed journals articles and the quality of journals, and strongly recommended to include them in the CV. The current results are also consistent with previous findings. ${ }^{13-16}$ Moreover, conference papers were recommended to be presented separately from publications. This finding is in accordance with Christenbery and Naylor et al, specifying that publications and presentations should be two separate sections within the CV. ${ }^{3,17}$

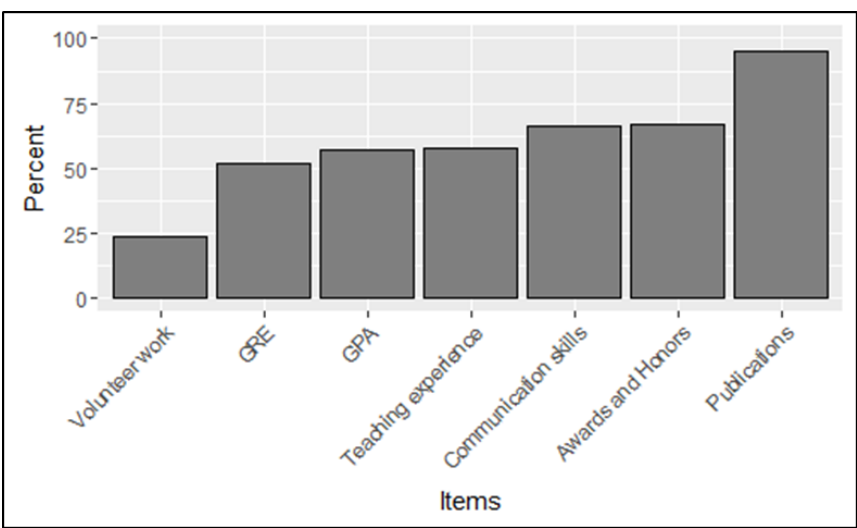

Figure 3: The proportion of respondents ranking factors important for an academic scholarship

Furthermore, it was found that the use of headings and bullet points as well as careful grammar and spelling revisions played an important role in the layout of the $\mathrm{CV}$ which is consistent with many other studies. ${ }^{11,18-20}$ For the content of the $\mathrm{CV}$, education and training background, research experience, and research interest are also essential parts along with publications as mentioned above. During the reviewing process, the majority of respondents firstly focused on whether candidates have any publications in journals indexed in the Web of Science.

One interesting point to mention is the different perspective of respondents from different continents regarding the inclusion of candidates' photographs on their CVs. According to the current survey, Asian and European respondents were likely to favour this practice, while respondents from the Americas advised not to include photograph on the CV. Noticeably, Ellis et al. and Leung et al. concluded that including a photograph was not recommended. ${ }^{11,20}$ In contrast, the guideline from Europass, an online portal structured by European Commission and Cedefop, suggested that the inclusion of photograph on CV was optional. ${ }^{21}$ One possible explanation for this difference may root in 
the cultural variability among different countries. During the pre-interview period of the scholarship selection, CVs can be seen as a blinded method of screening. The difference found in this survey may point out that respondents from America considered the organization of candidates' CVs to be more important than their physical appearance. This assumption may be consistent with the results that not many respondents considered religion and marital status important (Table II). Therefore, it may be important to have equality and diversity laws and guidelines with respect to different countries for inclusion of personal details in CVs.

Additionally, the present study found that communication skills were one of the important features that respondents looked for when recruiting a candidate for a scholarship (66\%). Previous studies have similarly shown that communication skills were ranked first as the most important group of skills in research candidate recruitment. ${ }^{22,23}$

As it is considered to be one of the most important components of a scholarship application, better CV preparation could increase the candidates' probability of getting the scholarship. ${ }^{24}$ It is worth noting that how candidates organize their CVs may also play a role in how effectively their abundant information is relayed to the selection committee. The current findings suggested that a scholarship CV should demonstrate the suitability of applicants by highlighting qualifications, achievements and other relevant information to the scholarship.

Through these results, a template of a CV was constructed (Table III) and recommended for potential scholarship applicants. A survey at Stanford University School of Medicine has shown that early involvement in research activities is a positive opportunity for medical students to acquire essential skills for a future career as a doctor including evaluating and integrating evidence critically. These skills are also important for doctors in the understanding of evidence-based medicine. ${ }^{25,26}$
Table 3: Recommendation for presentation of CV

\section{General layout}

Make use of headings and bullet points

Consider including photograph based on scholarship providers' preference

Check carefully for spelling and grammatical errors

Limit the number of pages according to content

Use chronological or reverse chronological order

Dedicate a separate section for publications

Separate conference and meeting section

Content of CV: Aims to make your CV relevant to scholarship

Personal information:

include name, date of birth, email address, phone number, home address, nationality, gender

Education and Training background: include undergraduate information, postgraduate information, courses including research educational course, management courses, training courses, and workshops. Qualification, national and international university ranking should be mentioned.

Publications:

include peer review articles, chapters, and books. A number of publications, quality of the journal, and the total citations should be mentioned.

Work experience, teaching experience

Research experience, research interest and ambition

Awards and Honours

Proof of language proficiency

Personal skills and competence

References

Highlight your CV by publications, awards and honours, communication skills

\section{Practical and theoretical limitation of the study}

Even though the study was carefully designed, there were some potential limitations in our findings. Firstly, the response rate was extremely low. This seems to be one of the usual limitations of onlinebased questionnaires, and it may be due to our emails targeting corresponding authors who were busy most of the time. The small number of respondents may cause some possible bias in the conclusion. Moreover, the data was obtained from 
corresponding authors of recent papers limited to the medical field so findings might not be generalizable to all kinds of CVs for scholarship applications. Another possible limitation is that the respondents were all researchers, so their heavy focus on publications may not capture the perspectives of other members in the scholarship selection committee.

\section{CONCLUSION}

In conclusion, the present study showed that publications in peer reviewed journals are the key feature in an outstanding CV. Moreover, an impressive CV for academic scholarships should be formatted with headings, bullet points, careful spelling and grammar revisions. In addition to publications, essential and impressive elements of an academic CV for a scholarship include education and training background, awards and honours, and communication skills. Research experience, educational research course, and management courses also play an important role. These findings were translated into a template $\mathrm{CV}$ that is presented in Table 3, and it is expected to provide prospective applicants an insight into the point of view of scholarship selection committees. We expect our findings will be able to help applicants become better equipped and strived to make an outstanding CV for scholarship applications.

\section{Declaration of interest statement}

The authors have no conflicts of interest to declare.

\section{REFERENCES}

1. Gölpek F. Price of higher education and individual demand. Procedia - Social and Behavioral Sciences. 2012;41:349-56.

2. Harolds JA. Tips for a physician in getting the right job, part II: the curriculum vitae, cover letter, and personal statement. Clinical nuclear medicine. 2013;38(9):721-723

3. Christenbery TL. The curriculum vitae: gateway to academia. Nurse educator. 2014;39 (6):267-8.

4. Sharma P. How to Write Impressive CV for Scholarship https: //scholarship-positionscom/ how-to-write-impressive-resume-forscholarship/2012/04/21/. 2012; Acessed 17 June 2019.
5. UK Ral. Medical Research Council The Application: https://wwwmrcacuk/funding/ guidance-for-applicants/2-the-application/ \#221. 2017; Accessed 14/08/2017.

6. Chandran L, Gusic M, Baldwin C, Turner T, Zenni $\mathrm{E}$, et al. Evaluating the performance of medical educators: a novel analysis tool to demonstrate the quality and impact of educational activities. Academic medicine : journal of the Association of American Medical Colleges. 2009;84(1):58-66.

7. Patel MV, Pradhan BB, Meals RA. Misrepresentation of research publications among orthopedic surgery fellowship applicants: a comparison with documented misrepresentations in other fields. Spine (Philadelphia, Pa : 1986). 2003;28(7):632-36.

8. Medford DAR. How to improve your curriculum vitae. British Journal of Hospital Medicine. 2013;74(Sup7):C98-C101.

9. Cleary M, Horsfall J. Keeping your curriculum vitae up to date. Journal of psychosocial nursing and mental health services. 2013;51 (6):4-5.

10. Thangaratinam S, Redman CWE. The Delphi technique. The Obstetrician \& Gynaecologist. 2005;7(2):120-5.

11. Ellis PE, Ellis SGS, O'Brien KD, Joshi RI. So you want to be a specialist registrar? - What to put in your CV. British dental journal. 2002;192 (3):133-6.

12. Mercer SJ. Components of the curriculum vitae important for short listing - a survey of newly appointed consultant anaesthetists. Anaesthesia. 2009;64(3):342-3.

13. Steinpreis RE, Anders KA, Ritzke D. The Impact of Gender on the Review of the Curricula Vitae of Job Applicants and Tenure Candidates: A National Empirical Study. Sex Roles. 1999;41 (7):509-28.

14. Conn DA, Asbury AJ. Importance of components of the curriculum vitae in determining appointment to senior registrar posts. Anaesthesia. 1994;49(7):623-6.

15. Barrett KE. Preparing Your Curriculum Vitae. Journal of Pediatric Gastroenterology and Nutrition. 2002;34(4):362-5.

16. Grimes DA. Sabotaging Your Curriculum Vitae. Obstetrics \& Gynecology. 2010;116(3):774.

17. Naylor DF. Identity Theft and the Academic Curriculum Vitae: How Do I Know You Are Who 
You Say You Are? Current surgery. 2005;62

(6):582-4.

18. Gallagher JC, Wodlinger Jackson AM. How to write a curriculum vitae. American Journal of Health-System Pharmacy. 2010;67(6):446-7.

19. Logan PM, Fraser DB. Constructing a curriculum vitae: the radiologist's resume. American Journal of Roentgenology. 1998;171 (4):923-5.

20. Leung AKC, Robson WLM. How to write an Effective Curriculum Vitae: Making the most of your asstes. Canadian Family Physician. 1990;36:2083-8.

21. European C. Intructions for using the Europass curriculum vitae. Available from: http:// fraeuropaeu/sites/default/files/ europass_instructions_enpdf. 2003.

22. Sheffield TUo. Skills Of Researchers. 1st ed. 2011.

23. Edge LN. Graduate Outlook Report. . Available from: http://wwwgraduatecareerscomau/ wpcontent/uploads/2015/06/ Graduate_Outlook_2014pdf. 2015.

24. Markey BT, Campbell RL. A resume or curriculum vitae for success. AORN journal. 1996;63(1):192-202.

25. Jacobs CD, Cross PC. The value of medical student research: the experience at Stanford University School of Medicine. Med Educ. 1995;29(5):342-6.

26. Nikkar-Esfahani A, Jamjoom AA, Fitzgerald JE. Extracurricular participation in research and audit by medical students: opportunities, obstacles, motivation and outcomes. Medical teacher. 2012;34(5):e317-24. 